\title{
El reto afectivo de la investigación interdisciplinar
}

\section{The affective challenge of interdisciplinary research}

\section{LUIS E. ECHARTE ALONSO}

Unidad de Educación Médica y Bioética, Facultad de Medicina, Universidad de Navarra

Instituto Cultura y Sociedad (ICS), Universidad de Navarra

lecharte@unav.es

Resumen. En este artículo analizo la dimensión afectiva de la actividad interdisciplinar tomando como hilo conductor algunos de los recuerdos autobiográficos que tengo vinculados a Mariano Artigas. Partiendo de una teoría de los sentimientos en la que lo racional y lo emocional aparecen íntimamente imbricados, defiendo que gran parte de las actuales dificultades para desarrollar estudios interdisciplinares derivan del actual divorcio razón/emoción en el que muchos investigadores son educados. En segundo lugar, identifico tres tipos de sentimientos que guardan una relación jerárquica y cuyo alcance es crucial, para la buena dinámica interdisciplinar: la excitación eureka, la catarsis narrativa y la experiencia extática. En la última parte del artículo ofrezco algunas recomendaciones para devolver los sentimientos al ámbito académico, sin que este pierda sus fuentes de financiación, y evitando males como el de la mercantilización del conocimiento y de los alumnos, el clientelismo y el cinismo.

Palabras clave: interdisciplinariedad; relación cognitivo-afectiva; Artigas; sentimientos intelectuales; identidad narrativa; experiencia extática. 
Abstract. In this paper I analyze the affective problem related to interdisciplinary research using, as a guiding theme, some of my autobiographical memories linked to Mariano Artigas. Starting from a theory of feelings that connects emotions closely to reasons, I defend that many problems in developing interdisciplinary research are caused by the current divorce reason/emotion in which many researchers are educated. Secondly, I identify three types of feelings in a hierarchical relationship, whose scope may be very extensive, in my opinion, for the good performance of interdisciplinary dynamic: eureka excitement, narrative catharsis, and ecstatic experience. In the last part of my paper, I offer some suggestions on how to return feelings to academic domains and, at the same time, keeping sources of funding, and avoiding present evils as commoditization of knowledge and students, clientelism, and cynicism.

Keywords: interdisciplinarity; cognitive-affective relationship; Artigas; intellectual feelings; narrative identity; ecstatic experience.

No es que haya una sola falsedad - nada de eso-, pero al cabo de diez renglones la verdad se pone a gritar y se precipita enloquecida y desgreñada por los corredores de su templo. 'Puedo soportar la mentira - exclama-, pero no sobrevivir a esta verosimilitud asfixiante’

Thornton Wilder

\section{Filosofía como terapia}

Por estas fechas se cumplen diecisiete años de mi primer encuentro con Mariano Artigas, allá por febrero del año 1999. En aquella época ocupaba parte de mi tiempo en estudiar las asignaturas del sexto y último año de la Licenciatura en Medicina, y una de ellas, Filosofía de la Ciencia II, era impartida por el profesor Artigas. Esto se explica porque el plan de estudios en el que tuve la suerte de caer tenía la peculiaridad de que el alumno podía matricularse, en un número limitado pero más que considerable de créditos, en cualquier asignatura ofertada en ese momento en la Universidad de Navarra. Dicho plan - se advertía a los alumnos al inicio del cursorespondía a un intento de fomentar ese espíritu interdisciplinar que es tan característico de la actividad universitaria.

Decidí orientar dichas asignaturas de libre configuración, así se las denominaba, a mi formación en el campo de la Filosofía. El motivo inicial 
que me condujo a dicha decisión fue el siguiente. El estudio de la medicina, con toda su complejidad y belleza, producía en mí gran inquietud puesto que, aunque proporcionaba gran número de respuestas, no eran todas las que por aquel entonces necesitaba. En mis investigaciones en el campo de filosofía de la mente suelo explicar esta carencia utilizando las siguientes dos imágenes. La psique humana es como una telaraña constituida por creencias que están unidas mediante argumentos y experiencias personales. Otra metáfora, menos intuitiva, es imaginarla como la desembocadura de un río, un ancho delta en el que convergen varias corrientes. Pues bien, es frecuente que, en las cabezas más jóvenes o inmaduras, dicha red sea más frágil. En la corriente de pensamiento de estos individuos suelen producirse mayores turbulencias. Este fenómeno no depende del número de nodos que componen la red o del caudal que carga el río, sino de la calidad de los lazos que mantienen unidos dichos nodos o, utilizando la segunda imagen, de la peculiar dinámica de fluidos que empuja el caudal de pensamientos.

Continuando con la narración, al inicio de mi etapa universitaria -se cumple ya un cuarto de siglo- creía en numerosas cosas y tenía facilidad para justificarlas con vehemencia, pero no de manera integrada. Esta ausencia de sentido en el discurso (especialmente en el discurso interior) venía acompañada de emociones negativas. El hastío era una de las más intensas. En efecto, recuerdo con nitidez que mis pesquisas en pos de la unidad de lo real empezaron siendo algo visceral, es decir, mis anhelos filosóficos estaban impulsados por un deseo de subsistencia que solo posteriormente llegaría a identificar con una búsqueda del fortalecimiento de la unidad del yo. Sea como fuere, el sufrimiento que me generaban inconsistencias y contradicciones fue disminuyendo gracias a estas primeras asignaturas de libre configuración. Podría decirse, no me avergüenza reconocerlo, que en esta primera etapa universitaria utilicé la filosofía con fines terapéuticos. No es el mejor de los fines pero es lo que fue. Al menos eso creo, pues las miradas retrospectivas son siempre sospechosas de revisionismo. Dejo a otros la tarea de discernir qué es reconstrucción y qué mera construcción.

Lo que aquí me interesa destacar es que la expresión emocional de esta cura intelectual y material estuvo marcada por un primer tipo de sentimiento, 
al que denominaré excitación eureka: la emoción de quien resuelve un problema importante o, cuanto menos, al que se le han dedicado muchas horas de reflexión. Es un sentimiento de victoria en el que, como ya expliqué, la propia identidad parece implicada, pues refleja, más o menos intensamente, una red de creencias fortalecida, unos pensamientos guiados hacia aguas mansas. Este tipo de sentimientos motivacionales ligados a la resolución de conflictos ha sido extensamente estudiado en el campo de la psicología y, más recientemente, está despertando el interés de la neurociencia (véanse, por ejemplo, los trabajos de Livet 2010, Pfister, Böhm 2008).

De entre todas las características que se adscriben a la excitación eureka, una de las más particulares es su carácter conclusivo: el problema que ocupaba al sujeto se vive como resuelto y, en este sentido, el proceso cognitivo suele darse por finalizado. Esto no significa que no se pueda iniciar, inmediatamente después, otra nueva reflexión. Es lo más probable, dado lo satisfactorio de la experiencia previa, la cual supone un refuerzo positivo que es insustituible en todo proceso de aprendizaje. Pero la atención es desplazada, aunque sea mínimamente, del objeto de atención inicial. Las consecuencias de esta experiencia son, en definitiva, ambivalentes: por un lado la tendencia al reposo de quien se siente saciado, por el otro, la inclinación al movimiento de quien persigue nuevos retos.

La importancia que tiene este primer sentimiento en el impulso de los primeros niveles de aprendizaje - y crecimiento- es clara y tenida en cuenta en la mayoría de los planes educativos contemporáneos (Fortier et al. 1995). También comienza a ser incluido entre los factores que se manejan para la elaboración de perfiles profesionales. Dime qué te emociona y te diré en qué podrías trabajar -y qué te falta y quién eres. El enfoque de las competencias - lo que se da mejor- parece estar llegando a su fin. Pero, ¿qué ocurre cuando las exigencias intelectuales conducen al científico a salir de su zona de confort, esto es, a ocuparse de asuntos que no le son atractivos por su particular personalidad? Encontramos aquí un primer escollo motivacional para el trabajo interdisciplinar y también una oportunidad para abrir nuevas vías de investigación. 


\section{Catarsis narrativa}

La aparición de un tipo de afecto diferente marca la que considero la segunda etapa en mi formación universitaria. El estudio de la historia de la filosofía y, sobre todo, la sintonía que mantenía con quienes la impartían, cambió en varias ocasiones la visión general que tenía de la realidad. Este cambio mental de paradigma venía precedido inicialmente, y por las razones esgrimidas en el epígrafe anterior, por un sentimiento de rechazo. Enfrentarse intelectualmente con distintos modos de pensar no es muy distinto de verse obligado a invitar a casa al enemigo. La percepción de amenaza que evocan no ideas puntuales sino enteras concepciones de la realidad es coherente con sentirse sostenido, en gran medida, por dicho tipo de narraciones e, implícitamente, con aceptar que si caen ellas cae también el individuo. Esta respuesta afectiva es probablemente una de las primeras grandes fuerzas que dificultan el trabajo interdisciplinar y en que sería conveniente que el sujeto aprendiese a detectar, comprender y manejar.

El cambio de una mentalidad a otra sigue un proceso lento, aunque, cruzado cierto umbral, el antiguo sistema de creencias - así lo recuerdosalta en pedazos. No obstante, el sentimiento asociado a esta catarsis narrativa -así la denominaré- no es negativo, como la angustia previa parece anticipar, sino un embriagador ; ahora lo entiendo todo! Se vivencia como un acontecimiento purificador - catártico - tan visceral como la excitación eureka, pero con cuatro grandes diferencias concatenadas. En primer lugar, es una experiencia íntima en la que se asume la totalidad de la realidad y del individuo. Segundo, la transformación es frecuentemente involuntaria -el estado de derrota no suele ser objeto de deseo. En tercer lugar, el cariz terapéutico de las catarsis narrativas es muy diferente al del éxtasis eureka: la sanación pasa por cierta experiencia de aniquilación. Por último, la catarsis no ejerce un significativo efecto de refuerzo en las siguientes transiciones. Veamos con detenimiento este cuarto asunto.

No suele pasar mucho tiempo hasta que el sentimiento de entenderlo todo comienza a oscurecerse con la sospecha de que el nuevo paradigma pueda llegar también a ser sustituido por otro aparentemente mejor. Es razonable 
esperar que este recelo se de más frecuente e intensamente entre aquellos investigadores que asumen el reto interdisciplinar, pues estos tienen la oportunidad de conocer y asumir otros mundos de manera más habitual.

El lado positivo es que dicho recelo interdisciplinar fomenta cierta actitud de provisionalidad, la cual cabría catalogarse de virtuosa, pues la humildad, en su sentido socrático, mueve al diálogo, que es un buen modo de seguir pensando las ideas propias y las ajenas. Es la virtud de quien asume que muchas dificultades, y angustias, están relacionadas con una manera equivocada de entender el mundo -o al menos buena parte de él-. Thomas Kuhn describe este modo de mirar como el de aquel que, antes de enfrentarse a un problema, es capaz de preguntarse si está bien formulado, en otras palabras, si merece ser disuelto y no resuelto (Kuhn 1968, 144 y 167). Análogamente, en términos identitarios, puede definirse como el sentimiento de quien se pregunta si la mejor manera de seguir avanzando es cambiarse a sí mismo y no simplemente cambiar el mundo circundante.

El lado negativo está en que, si la actitud socrática facilita las labores interdisciplinares, también se acompaña de un importante efecto adverso: el debilitamiento de las convicciones - utilizando mis dos metáforas, la humidad intelectual adelgazaría los lazos entre creencias e introduciría turbulencias en la corriente de consciencia.

Otra segunda causa que intensifica la experiencia de fragilidad en el investigador interdisciplinar son los vestigios de la configuración previa que todo cambio de mentalidad arrastra, en especial aquellos iniciales adquiridos en la infancia (Mosak y Maniacci 1999, 30-45). Estas cicatrices en la red de sentido - que se presentan en forma de creencias y prácticas de vida que no guardan ninguna coherencia con el presente planteamiento vital del individuo - aumentarían la inestabilidad de la red.

El sentimiento negativo de exposición es, en definitiva, una segunda fuerza que el investigador interdisciplinar ha de aprender a gestionar. De lo contrario, lo más común es que se acaben disparando, voluntaria o involuntariamente, algunos bien estudiados mecanismos de defensa psicológicos: los orientados a preservar la cordura del sujeto - su identidad o red de 
creencias. Por supuesto, estos mecanismos tienen el costo de impedir el encuentro del sujeto con lo real. La selección sesgada de información, la tergiversación de información, o la racionalización son algunas de estas estrategias de autoengaño (Levine 2014; McCornack 1992). Pero de entre todas, la más particular y específicamente humana es la manipulación intersubjetiva. Me explico. Uno de los más sofisticados y perfectos estados de autosugestión es el de quien logra convencer a un número suficiente de personas de aquello que le gustaría creer (von Hippel y Trivers 2011). Cumplido el objetivo, solo queda evitar codearse con extraños. El esnobismo del esbirro intelectual, como se comprenderá, poco tiene que ver con la abierta curiosidad de discípulo.

Desafortunadamente, mi experiencia en el campo de la investigación interdisciplinar confirma lo que acabo de formular. Los que hemos emprendido dicha vía somos también los más propensos a acabar atrincherados en alguna postura intelectual -estación término de toda indagación de campo o fuera de campo-. Y no hay que subestimar la violencia de este tipo particular de fanatismo: la indiferencia, el flemático interés o la más vehemente actitud condescendiente representan intensas expresiones de aversión y, en según qué circunstancias, dañinas agresiones.

Volviendo al pasado, recuerdo que el agotamiento mental solía también abonar en mí dichas estrategias que, por otro lado, no desentonaban demasiado de los foros intelectuales que, como tabernas, frecuentaba. Desde luego, sería interesante estudiar hasta qué punto dicho clima tóxico está relacionado con ciertos trastornos depresivos que padecen cada vez más estudiantes y profesores universitarios, con algunos tipos de somatizaciones $\mathrm{y}$, por supuesto, con el consumo de sustancias adictivas (Eisenberg et al. 2007, Blix et al. 1994). En la misma línea, otro asunto que merecería especial atención es el fenómeno de transición del dogmatismo involuntario hacia el cinismo consentido. Por lo dicho y, sobre todo, por mi experiencia de casi ya 25 años, creo que llega un momento en el que al intelectual le es imposible no ser consciente de las malas prácticas argumentales que utiliza y en las que se instala. 


\section{Relaciones académicas}

En ocasiones, la memoria es más poderosa que los mecanismos que nos protegen contra la desestructuración del yo. La ventaja de dicha debilidad es que resulta también una gran aliada contra las actitudes arrogantes. Dije que una característica común entre los que inician el periplo interdisciplinar es descubrir que las cosas no son tan sencillas como se presentan allí de donde vienen. Y la experiencia de verse convertido, a medio camino de este viaje, en aquello en lo que antaño se creyó haber superado es un excelente revulsivo contra tal cambio. Mi caso concreto resulta paradigmático puesto que entre los profesionales de la medicina la presunción es bien conocida (Berger 2002).

Antes de proseguir es necesario romper una lanza en favor de los médicos. La arrogancia es un defecto difícilmente evitable en una actividad en la que, por un lado, se pone en juego un bien hoy muy valorado - la salud-y, por el otro, se trabaja con un tipo de "clientes" con los que se establece una particular relación fiduciaria, esto es, la de vínculos basados en la confianza. No es fácil ser humilde cuando trabajas diariamente con personas que te consideran casi un dios (Shem 2002). En contraste, los profesores universitarios no suelen sufrir este tipo de inducción psicológica - alumnos y colegas se cuidan mucho de ello-. Otro segundo importante atenuante se encuentra en la formación pre-universitaria. Desgraciadamente, la moda imperante es que a los niños con mejores calificaciones se les aconseja estudiar carreras de ciencias, mientras que a los obtienen peores resultados se les recomienda elegir carreras de letras (Silván, Cuadrado y López-Sáez 2012; Aunión 2008). Es fácil que dicho sesgo influya en la futura impresión que se puedan causar ambos grupos de profesionales entre sí, y también en las relaciones afectivas que puedan establecerse entre ellos. Sin duda, ahondar en el estudio de este fenómeno podría servir para encontrar remedios para superar el actual divorcio entre las dos culturas.

En mis últimos años de carrera tuve que enfrentarme a dos problemas más graves que los de la arrogancia y los enmascarados complejos de inferioridad: el desencanto y el pragmatismo. Empezaba a comprender que no 
solo los médicos sentían animadversión por la filosofía. Ocurría también a la inversa y, aunque veladamente, de manera tanto o más intensa. Este descubrimiento - puedo recordar hasta el cuarto de estudio en el que se produjo- constituye otro de los hitos biográficos que el paso del tiempo no ha conseguido borrar.

El pensamiento cayó sobre mí como un rayo: el ideal interdisciplinar no solo era una quimera sino una actividad de riesgo y, por tanto, lo mejor era instalarme en un único campo. Puestos a verme forzado a convertirme en un hombre de seguras convicciones -en el peor sentido de la expresión, la de quien no reflexiona seriamente acerca de sus creencias y decisiones o, lo que es peor, la de quien finge hacerlo- zanjé decantarme por la medicina por estar socialmente bien considerada y mucho mejor remunerada. Así hubiera sucedido si, como anticipé al inicio de este artículo, en el último semestre de la carrera médica no hubiera tenido por profesor a Mariano Artigas. A su asignatura van ligados un tercer tipo de sentimientos, que he aprendido a valorar extraordinariamente y que delimitan la que considero la tercera etapa de mi formación universitaria.

José Ángel García Cuadrado lo describe de la siguiente manera: "pasó su vida sin hacer ruido, sin espectáculo, con sencillez y naturalidad” (2007, 467). Soy testigo directo: sus clases reflejaban la personalidad de un hombre sereno, discreto y paciente. Había alumnos que confundían estos rasgos con los propios de la timidez - algunos para tratar de tomar ventaja- aunque solían salir pronto de su error. Era un hombre fuerte y de hablar franco y directo. En lo que concierne a la docencia, destacaría la claridad con la que impartía unos temas que, como tampoco se cansaba de repetirnos, eran de suyo difíciles y problemáticos. Los que nos dedicamos a la docencia sabemos lo difícil que es producir discursos con sentido para el alumnado sin que, con ello, sea sacrificada la veracidad.

También me llamaba especialmente la atención que, siendo patente que poseía profundas convicciones - ahora en el buen sentido de la expresión-, no solía utilizar con sus alumnos argumentos tajantes. Aún más, no era de esa clase de profesores de discurso totalizante y capaz, por ello mismo, de 
generar esas catarsis narrativas descritas arriba y que eran tan de mi gusto. $\mathrm{Al}$ menos así me explico ahora por qué no solía salir saciado de su aula.

Antes de proseguir con el tercer sentimiento intelectual es preciso que haga una importante puntualización. Cada vez estoy más convencido de que algunas catarsis narrativas dependen menos de la calidad del discurso y más de la oportunidad en el que este se formula - de las circunstancias de los oyentes $-\mathrm{y}$, por supuesto, de las habilidades retóricas del orador. Un ejemplo de tal oportunismo es el drama que acontece en ciertos foros interdisciplinares en los que parte de los investigadores, por la autoridad que goza un determinado campo, encandilan al auditorio con tecnicismos y extrapolaciones que no tolerarían sus colegas de campo. Y a la inversa, como otros investigadores, por arrastrar el sambenito de su especialidad, son constantemente ninguneados (Gaitán y Echarte 2016). Embaucadores han existido siempre, pero la tendencia contemporánea a la hiper-especialización está fomentando el aumento del número de tales maleantes e incautos.

Una muestra reveladora del poder de la retórica lo encontramos en el caso del orador que, víctima de su propia magia escénica, lamenta no haber encendido la grabadora de voz en ese instante en el que, explicando un tema, creyó haber entendido un fenómeno - fenómeno que es simultáneo con la impresión colectiva de unos alumnos que también creyeron haberle entendido-. Lástima que el poder persuasivo de determinados argumentos desaparezca caído el telón. Por supuesto, hay veces en los que la creencia es verdadera, pero menos de las que nos gustaría imaginar (Echarte 2012). Lo cortés no quita lo valiente. Soy de los que creen que el aula es un marco magnífico para ponerse a pensar y que los alumnos - por no hablar de otros especialistas - suponen una extraordinaria ayuda en dicha tarea.

¿Qué estrategias psicológicas serían convenientes para lograr la mínima equidistancia dialógica para entablar un sincero diálogo interdisciplinar? ¿Cómo evitar los espejismos retóricos? ¿Es posible diferenciarlos de los verdaderos hallazgos fruto del pensamiento colectivo? Creo que el estudio de los procesos afectivos podría ofrecer algunas importantes claves sobre tales asuntos que afectan sin duda al corazón de la investigación interdisciplinar. 


\section{La mística de la ciencia}

Como iba diciendo, el profesor Artigas no despertaba grandes pasiones en el aula. Asunto distinto era lo que sucedía fuera de ella, en el tiempo en el que estudiábamos la materia. Son pocas las asignaturas que, como la suya, me han evocado sentimientos tan hondos y permanentes. Recuerdo, en especial, que sus reflexiones sobre el método de las ciencias cambiaron mi comprensión sobre la naturaleza de la actividad universitaria y también mi actitud hacia la institución (Artigas 2009, 151-193). Me permitieron ver con nuevos ojos lo que solo percibía ya como un conjunto de muros. Es difícil describir esta experiencia extática, llamémosla así. Tengo hasta recelos de utilizar dicho término en tanto que pueda llegar a identificarse con algún tipo llamativo de estado alterado de la conciencia o asociarse con particulares credos religiosos o incluso con las secuelas ocasionadas por nocivos hábitos psicofarmacológicos. Nada de esto. De entre los sentimientos aquí mencionados, la experiencia extática es probablemente el más frecuente (aunque, por sutil e inefable, el que pasa más desapercibido entre los investigadores) y también aquel cuyo cultivo abre un horizonte de posibilidades de extraordinaria fuerza motivadora.

La experiencia extática se asemeja a la excitación eureka en el modo en el que gira en torno a un particular objeto o evento externo y no tanto, como en la catarsis narrativa, a una experiencia interna, reflexiva, de conversión - aunque pueda derivar en ella-. En otras palabras, no es primariamente el sentimiento de haber cambiado uno mismo sino el de traspasar una puerta de lo real que, sin entender muy bien cómo, se ha abierto (Eco 1999, 101-103). A ello apela etimológicamente la palabra éxtasis: a la acción de salir de sí, de desplazarse hacia fuera. Por ello, la experiencia extática suele asociarse a los sentidos y, en especial, a la visión. No casualmente, muchas obras artísticas toman la mirada - mayestática- como principal motivo representacional del éxtasis: traspasar con la mirada y contemplar lo que nadie, a simple vista, percibe (Warma 1984, Arnheim 1954). Y efectivamente, dudo que sin el substrato material que tiene la actividad interdisciplinar universitaria (aulas habitadas, pizarras borroneadas, interminables estantes 
de libros, el olor de los laboratorios...) hubiera experimentado en plenitud este tercer sentimiento, o al menos con la suficiente intensidad como para que despertase mi curiosidad.

Un segundo rasgo de la experiencia extática, más cercano ahora a la catarsis narrativa, es la sorpresa que causa esta apertura. Creía haber entendido, ipero no! Sin embargo, a diferencia de la catarsis narrativa, el sentimiento es de abobamiento, es decir, al sentimiento de máxima comprensión. Conlleva percibir la insuficiencia de las categorías conceptuales manejadas hasta ese momento para entender una realidad que, en ese preciso instante, manifiesta visos de infinitud (Peñalver Gómez 1997, 14-16). Encontramos aquí otro sentido diferente por el que la experiencia extática apela a la trascendencia: impide el atrincheramiento intelectual del individuo sobre sí. Este tipo de humildad prudente no genera, por tanto, el efecto adverso de la fragilidad y, por ende, la subsiguiente arrogancia. La razón es que, a diferencia de la catarsis narrativa, tal humildad no viene por la sospecha de lo que el futuro pueda deparar, por la comentada provisionalidad de los conocimientos adquiridos, sino porque las categorías empleadas para entender la realidad no se ajustan, aquí y ahora, a las vivencias contemplativas que se tienen de ella. El impulso a quemar la propia obra y empezar de nuevo, o incluso a renunciar a la vía intelectual, son quizá las únicas tentaciones reprobables de la experiencia extática.

Otra particular característica de la experiencia extática es que, a pesar de que hace explícita la pobreza del pensamiento, no tiene coste para la identidad. Al contrario, la refuerza por dos razones. Primero, porque introduce una creencia fundamental y máximamente cohesiva: la realidad - o gran parte de ella- es buena y luminosa. Es fácil sostener una identidad en un mundo menos amenazante de lo que el individuo espera. Y en segundo lugar, porque el objeto de contemplación refiere a la entera realidad, es decir, descubre una relación armoniosa con el todo al que pertenece. Como suele decirse, nadie puede amar realmente algo y evitar que ese amor acabe extendiéndose. Esta experiencia impele al observador a afirmar la realidad, a protegerla y, en última instancia, a participar del orden cósmico. Y en efecto, saberse integrado en este facilita la permanencia en uno mismo. Encontramos 
aquí otros modos de entender la trascendencia de la experiencia extática: en cuanto al objeto de conocimiento, que desvía la mirada del observador hacia otros objetos, y en cuanto al cognoscente, que deja de ser el centro de gravedad de los fines que mueven la acción.

David Peat describe del siguiente modo este sentimiento que, a su juicio, todo el mundo ha experimentado alguna vez:

una notable sensación de intensidad que parece colmar de significado todo el mundo a nuestro alrededor [...]. Sentimos que estamos tocando algo universal y quizá eterno, así que ese instante particular en el tiempo adquiere un carácter luminoso y da la impresión de expandirse en el tiempo sin límite. Sentimos que todas las fronteras entre nosotros y el mundo exterior se desvanecen porque lo que estamos experimentando cae más allá de todas las categorías y de todo intento de capturarlo en pensamientos lógicos. (Peat 1991, 56)

¿Cómo se abre dicha puerta? Para mí sigue siendo un misterio la manera en la que el estudio del método de las ciencias me ayudó a valorar este tipo de experiencias tan íntimamente asociadas a la actividad universitaria. Pero sin duda fueron las que me convencieron de que si algo define el filósofo es el amor a la sabiduría, y no la cantidad o el tipo de conocimiento poseído pues solo este (verdadero) filósofo, como Benedicto XVI afirma, "sabe enseñar el arte esencial [...] indicar verdaderamente el camino de la vida” (Spe Salvi, 6).

Por supuesto, como lo propio del amante es abordar enteramente al amado, este singular buscador de conocimientos profesará inquietudes interdisciplinares. Aunque de ello no se deriva que la inclusión en uno u otro campo-no importa si de ciencias experimentales o humanidades-o incluso la más completa actividad interdisciplinar haga al filósofo lo que es.

Finalmente, decidí quedarme en la universidad: la actividad era viable y el pago, aunque en especies, mayor que el de un cirujano plástico. Mis expectativas no fueron defraudadas. Hoy más que nunca comparto con Peat la creencia de que la experiencia extática representa el más poderoso motor de un investigador: con ella se superan los males y riesgos aquí mencionados y también gracias a ella se hace posible la consolidación de equipos interdisciplinares de trabajo. 


\section{Materia humana}

El tema de estudio que elegí en mi proyecto de doctorado, al que di por título "Intencionalidad, sentido e identidad" respondía a un intento por ordenar las inquietudes y descubrimientos que me habían acompañado en mis años de carrera, y por reflexionar sobre ellas. ¿Qué relación guarda el sistema de creencias con la identidad humana y, sobre todo, con la capacidad para trascender lo real o, mejor, para que lo real se abra al individuo? Era un tema difícil, de madurez, como dicen algunos. Pero hice mía la frase de Alejandro Magno: Si espero, perderé la audacia de la juventud. Ahora tengo más razones que entonces para defender tal decisión. La pasión es un valor en alza en las batallas intelectuales.

Me introduje en un bosque inmenso en el que aprendí a perderme. Como era de esperar, la defensa de mi tesis doctoral no supuso una gran aportación al saber. Sin embargo, pecaría de falsa humildad si no reconociera el gran valor formativo que tuvieron para mí aquellos años. Y aunque fui el principal beneficiario de mi estudio, quiero pensar que posteriormente también ha servido para provecho de mis congéneres.

Son cada vez menos los que tienen la oportunidad de tomar tales desvíos pues en la universidad contemporánea se está invirtiendo el orden de prioridades. Hoy son más los que creen que es porque el alumno aprende cosas útiles para la inserción laboral por lo que puede sacar beneficio de su formación. De ahí que las tesis doctorales que hoy se estilen sean las que se ocupan de temas bien determinados que den respuesta a problemas actuales igualmente concretos. Este enfoque utilitarista, y sobre todo desapasionado, de los programas de doctorado y, en general, de la entera universidad trae graves consecuencias. Tal como antes esgrimí, la desconexión (afectiva) con lo más íntimo de lo real provoca males de tristeza, envidia, nepotismo, ideología, conformismo, hastío... No hay salario suficientemente alto para compensar tales males. Pero además, impide comprender el verdadero espíritu de toda regla y el sentido de toda meta individual o social. ¿Cómo puede entonces la institución universitaria preparar alumnos para una vida socialmente productiva e integrada? La inversión de prioridades no 
es aceptable ni siquiera desde parámetros utilitaristas. Precisamente sobre esta cuestión encontré hace poco una cita de otro de los grandes profesores, Leonardo Polo, a cuyas clases tuve la fortuna asistir durante todo un año -y dos veces por semana. En una conferencia a profesores impartida en 1994 en la Universidad de Piura, y publicada en 1996, Polo afirmará: "El amor a la verdad insisto es lo más importante en la formación de un hombre. No hay ética posible, no hay comportamiento recto si no se ama la verdad, porque el comportamiento no recto consiste en admitir la mentira en la propia vida" (Polo 1996).

No pensemos, sin embargo, que los licenciados en filosofía están a salvo de esta epidemia del metal. Como critica el filósofo Peter Kingsley “en lugar de amor a la sabiduría, la filosofía se está convirtiendo en el amor a hablar y discutir sobre el amor a la sabiduría. [...] hablar y discutir han expulsado del panorama a todo lo demás” (Kingsley 2014, 38). La tan apreciable objetividad está sucumbiendo al objetivismo incluso entre aquellos que deberían estar más preparados para entender la diferencia entre ambos términos.

En este escenario de desencanto académico, que lleva un par de siglos arraigando en Occidente, se comprende también que algunos hayan llegado al extremo de pensar que es precisamente la experiencia extática el principal rasgo que diferencia al artista del científico y del filósofo. Por ejemplo, Joseph Conrad, sobre la búsqueda de la verdad que emprende el artista, escribe lo siguiente:

El artista [...] si lo merece y es afortunado, encuentra los términos de su invocación [...] Su invocación es menos sonora, más profunda, menos clara, más perturbadora [...] y se olvida pronto. Sin embargo, su efecto dura para siempre. La sabiduría cambiante de generaciones sucesivas descarta ideas, cuestiona hechos, echa abajo teorías. Pero el artista apela a esa parte de nuestro ser que no depende de la sabiduría; a lo que en nosotros es un don y no una adquisición [...] y es, por tanto, más permanentemente duradero. Habla a nuestra capacidad de dicha y sorpresa, al sentido de misterio que rodea nuestras vidas; a nuestro sentido de la piedad, y de la belleza, y del dolor; al sentimiento latente de la camaradería con toda la creación [...] y a la sutil pero invencible convicción de solidaridad que entrelaza la soledad de innumerables corazones con la 
solidaridad en los sueños, en la alegría, en la pena, en las aspiraciones, en las ilusiones, en la esperanza, en el miedo que une a unos hombres con otros, que une a toda la humanidad [...] los muertos con los vivos y los vivos con los que aún no han nacido. (Conrad 1945, 3)

Esta magnífica descripción de Conrad no difiere, en lo esencial, de experiencias extáticas como las que relatan académicos de la talla de Kurt Gödel, Erwin Schrödinger o Arthur Stanley Eddington (Álvarez et al. 1998). Sí que es cierto que Conrad pone especial énfasis en el viaje hacia el interior que conlleva dicho sentimiento aunque, por otra parte, otorga una extraordinaria importancia a la memoria. El olor de los puertos, el aullido de los tifones, las picaduras de los mosquitos... son recuerdos que Conrad recupera desde la mesa de su escritorio londinense. Sin esas experiencias reales de sus viajes no le hubiera sido posible construir esos geniales relatos que consiguieron conectarle a él, y posteriormente a sus lectores, con aquello que las apariencias habitualmente velan.

La posición de Conrad sobre la memoria y la imaginación contemplativa trae a colación otro de los grandes interrogantes asociados a la experiencia extática. ¿Cómo es posible distinguir entre un auténtico encuentro con lo real y un mera alucinación? Son muchos los autores que han tratado de encontrar algunos elementos diferenciadores a partir del estudio comparado de narrativas, incluidas las de pacientes psiquiátricos, aunque lo único que parecen tener claro todos ellos es que, por la propia naturaleza del objeto de estudio, resulta imposible encontrar pruebas irrefutable (Huxley 2005). Como acabo de comentar, un error común a nuestro tiempo es deducir de dicha conclusión que las experiencias extáticas son irrelevantes para la actividad intelectual y, en última instancia, que no tienen papel alguno para el buen vivir.

Otro enigma asociado al anterior, que ha pasado a integrar gran parte de mis actuales inquietudes existenciales -y proyectos terapéuticos - es el de las teorías elaboradas desde la más desapasionada objetividad. Indudablemente, hay elementos de la realidad a los que es posible acceder con claridad, precisión y sin débito sentimental alguno. Ocurre incluso con los 
objetos más comprometidos. Es posible llegar a ser un erudito, por ejemplo, en el tema de los derechos de los pacientes y al mismo tiempo sentir por ellos completa indiferencia; o estudiar la naturaleza de las emociones sin gozar de apenas empatía por el congénere; o publicar innumerables artículos sobre los fines de la universidad sin sentirse atraído por ellos.

Este tipo de conocimientos producidos por hombres de hojalata -llamémosles así- se encuentran en las antípodas de los ocasionados por los hombres de paja-aquellos cuya vivencia sentimental es tan intensa que sufren el enclaustramiento tan típico de las catarsis narrativas. Con todo, parece haber una gran diferencia entre ambos: la que existe entre el docente y el potencial maestro. Porque si bien es bueno escuchar a los primeros no lo es imitarlos. Solo los segundos han iniciado la vía de la acción y, parafraseando a Conrad, muchos conseguirán hacer de esta vía una invocación que obtenga respuestas. Es ese paso al estado en el que la sabiduría y la felicidad llegan a identificarse el que merece algo más que una reflexión.

Cierro el epígrafe y también la metáfora ligada al imaginario mundo de Lyman Frank Baum con una última consideración, que me servirá para introducir las conclusiones. Es factible que los hombres de paja lleguen a ser premiados con un cerebro, al menos aquellos que hayan logrado no sucumbir al fuego académico. Sin embargo, por la naturaleza de su actividad -o inactividad-, los hombres de hojalata difícilmente tendrán la oportunidad de que se les haga entrega de un corazón. Huelga decir que todos estamos rellenos, en unas u otras proporciones, de algo de metal y algo de paja.

\section{Un lugar para el reposo}

¿Qué consecuencias puede tener para la universidad -ámbito por excelencia de la actividad interdisciplinar- que llegue a estar reglada con criterios objetivistas, es decir, dirigida por hombres de hojalata? Veamos algunas razones por la que este no es el mejor enfoque para establecer caminos ni son aquellos los mejores candidatos para guiar - mover a la acción- a una comunidad científica. 
Uno de los grandes riesgos del objetivismo es que la institución acabe cediendo a intereses partidistas y que sus miembros se conviertan en mercenarios del conocimiento trabajando para el mejor postor. Por un lado, porque la tesis de que el conocimiento tiene valor en sí mismo es difícilmente objetivable, y por el otro porque, si el conocimiento no proporciona satisfacciones, es lógico que el profesor acabe buscando su felicidad en otros lares. Y lo mismo ha de ocurrir con los motivos por los que un alumno escogerá entre varias universidades. ¿Qué me puede ofrecer está a cambio del sacrificio de aprender? Esta nueva sensibilidad de la que muchos gestores acaban siendo cómplices es, bajo mi consideración, la primera causa por la que el proceso de Macdonalización de la sociedad, tal como es definido por Stjepan Meštrović, está extendiéndose en las instituciones académicas (Meštrović 1997, 73-74). Lo esencial se pierde o, lo que es peor, se desvirtúa para hacer más asequible al gusto del consumidor aquello que se ofrece -el consumo masivo de sucedáneos_.

Entramos en un círculo vicioso. La progresiva instrumentalización de la universidad suele ir seguida de la desintegración de la unidad orgánica de sus facultades. Y a la inversa, una formación e investigación más y más híperespecializada relega la cuestión de los fines a la marginalidad. Prueba de ello es que está de moda pensar que es la sociedad la que debe marcar la dirección hacia la que la universidad ha de dirigirse - formando alumnos capacitados y proporcionando conocimientos prácticos y tecnología-. Otro signo es el creciente número de universidades que confían ingenuamente en métodos de gestión que apenas difieren en nada de los de cualquier otra empresa en la que reina la ley de la oferta y la demanda. Y se quiera o no, es inevitable que la utilización de métodos para cuantificar el trabajo del profesor/alumno potencie aún más el clima objetivista, clientelista e ideológico.

Según el parecer de José Miguel Cortés, filósofo y actual director del Instituto Valenciano de Arte Moderno (IVAM), el proceso de Macdonalización está afectando también al arte.

[E]stoy totalmente en contra de que se valore una institución cultural, sea una filmoteca, sea un teatro, sea un museo, del mismo modo que se valora, por decir 
algo, una fábrica de coches o de muebles. Por visitas u otras métricas similares. Lo importante en una institución cultural no es el número de personas que acuden a la misma a ver una película o una exposición, lo realmente destacado es cómo esa institución cultural es capaz de crear un espacio de debate cultural. De qué manera esa institución nos enriquece culturalmente. Por lo tanto, pienso que hay que evaluar la gestión y el impacto de una institución como la nuestra desde parámetros culturales, no mediante parámetros mercantilistas (Cortés 2016).

Cortés conserva la idea clásica de que las instituciones culturales deben ocuparse principalmente de los fines. Esa es precisamente su función: cambiar a la ciudadanía. No obstante, este tipo de declaraciones son consentidas en ámbitos como el del arte, donde se perdona casi todo. Pero ¿cuántos profesores de la universidad se atreven a enfrentarse a sus alumnos y gestores con semejante argumento? Lo más probable es que sean tachados de sentimentales. Y tendrían razón si no fuera porque la utilizan en el sentido romántico de la expresión. Vuelvo otra vez sobre lo mismo, hemos de devolver a la ciencia y a la filosofía aquello que nunca fue singular del arte. Y todavía debería ir más lejos: ni siquiera son estos los depositarios últimos de tales tesoros. Como concluye Rachel Carson en El sentido del asombro, "los placeres que perduran al contacto con la naturaleza no están reservados para científicos sino que están al alcance de cualquiera que se sitúe bajo el influjo de la tierra, el mar y el cielo y su asombrosa vida" (Carson 2012, 47).

¿Merece la pena mantener abierta una universidad si esta pierde el fin fundacional por el que recibe el nombre? Es innegable que las escuelas de formación técnica tienen una función social, pero esta no puede confundirse con las primeras pues, a la postre, acabarán perdiendo también todo valor. Pero seamos justos y hagámonos también la pregunta contraria. ¿De qué sirve un modelo no sostenible de universidad, por buena que sea? ¿Cuál es la mejor de las gestiones en una institución científica? No son preguntas sencillas. Cerraré este artículo ocupándome de la segunda por ser la que más relación guarda con el problema sentimental.

Creo que la clave consiste en aceptar las dificultades que presenta todo gobierno de artistas. Si lo dicho hasta ahora no ha surtido suficiente efecto 
y resulta dura tal expresión, sustitúyase por la de gobierno de quienes se afanan en profesiones liberales, pero en la acepción empleada por el cardenal John Henry Newman, esto es, la de quienes trabajan en una actividad en la que los más importantes beneficiarios son los propios agentes de la acción, y entre cuyas tareas acaban encontrándose unos y otros hasta formar comunidad (Gutierrez 2013).

La razón por la que hablo de una Universidad en los términos que he utilizado es que no solo ocupa simplemente todo el territorio del saber, sino que es el territorio mismo; que pretende mucho más que acoger y alojar, como en una posada, todo arte y toda ciencia, toda historia y filosofía. Lo que en verdad pretende es asignar a cada campo de estudio que imparte su propio lugar y sus justos límites; definir los derechos, establecer las relaciones mutuas y facilitar la comunicación entre todos y cada uno de ellos; contener a los ambiciosos y a los invasores, y mantener y socorrer a aquellos que de vez en cuando sucumben bajo los que gozan de mayor popularidad o de circunstancias más afortunadas; salvaguardar la paz entre todos y encauzar sus diferencia y sus contrariedades hacia el bien común. [...] Y la Universidad aprende a hacerlo, no por la aplicación de reglas estrictas, sino por la sagacidad, sabiduría y tolerancia; actuando con una profunda comprensión de la materia y contenido del saber y mediante la vigilante represión de cualquier agresión o fanatismo en cualquier sector. (Newman 2011, 39-40)

La descripción que hace Newman de la institución universitaria se ajusta a la de un gobierno autónomo, es decir, el que goza de abundante independencia en la creación y aplicación de unas leyes que se dictan para el bienestar de los que habitan el territorio donde se aplican. En él tienen cabida todos los que comparten ese ideal que hace de un simple grupo de gente la más viva comunidad. "Porque promete admitir - sin temor, sin prejuicio, sin componendas - a todos los que llaman a su puerta, si vienen en nombre de la Verdad" (Ídem). Y por el contrario, de su supervivencia depende frenar a quien, desde fuera o desde dentro, incite la falacia o promueva la violencia, por muchos réditos que tal individuo pueda generar. Y la peor violencia es la del escándalo - en el que la emoción lo es casi todo-, un problema al que todo gobernante prudente han de saber enfrentarse: no vale escudarse en tal 
para evitar las tareas más onerosas de gobierno ni mucho menos pretender vencerlo eliminando a los testigos pues, de todos, el mayor escándalo es la negación del mal.

Pareciera, bajo dicha descripción, que a este tipo de comunidades solo pueden pertenecer los muy ricos, capaces de financiarse a sí mismos, o los más pobres, los que tienen únicamente el deseo de conocimiento. Ambos grupos conforman un número muy pequeño, e incluso estos han de enfrentarse a ciertos problemas particulares a su condición. No me detendré a examinar estos problemas pues prefiero centrar la atención, en el último epígrafe de este artículo, hacia aquellos propios del grupo al que pertenecemos la mayoría de los ciudadanos de ese peculiar microestado que es la universidad.

\section{Encadenar los eslabones de la autenticidad}

Todo está inventado. Durante siglos, el mecenazgo ha sido la manera en la que la universidad ha logrado financiación externa sin perder su independencia e identidad. Pero, ¿quién da dinero a fondo perdido? Repasemos la lista de candidatos.

En primer lugar, los más predispuestos a colaborar más comprometidamente son los que entienden que el valor en sí mismo que posee la actividad universitaria está muy por encima de los otros servicios que esta pueda prestar al inversor. Estos mecenas suelen ser los que han tenido la suerte de disfrutar de la búsqueda de conocimiento y desean que otros corran la misma suerte. Aquí topamos con uno de los fundamentos del inalienable vínculo entre la investigación y la docencia. Mucho menos entusiasmo albergan los del segundo grupo, aquellos que reconocen que son necesarias instituciones que reflexionen sobre la idoneidad de los fines hacia los que la sociedad se dirija. Juristas, políticos, padres de familia... El tercer grupo de potenciales colaboradores está integrado por quienes saben que la mayoría de los frutos de la investigación interdisciplinar se recogen a muy largo plazo. Es comprensible que, en el mundo frenético y desesperanzado en el que vivimos, sean estos los que menos interesados estén en financiar 
proyectos interdisciplinares. (Bonnie 1988). El cuarto grupo es el compuesto por los que esperan resultados a corto plazo. Lógicamente, sus integrantes no merecen ser llamados mecenas.

Muy a nuestro pesar, las estrategias que emplean los que, por profesión, ejercen la noble tarea de buscar dinero para la universidad suelen empezar por el cuarto grupo. Este dinero representa el principal caballo de Troya de toda comunidad científica pues supone la aceptación de unos compromisos que socavan toda posible intimidad con lo real. No obstante, apenas se puede achacar nada a estos buscadores de tesoros pues, por un lado, el cuarto grupo es el más numeroso y, por el otro, apenas disponen de las herramientas conceptuales para entender las consignas que repiten con vehemencia: la universidad no es una empresa. Los que sí tenemos grave responsabilidad somos los propios investigadores y docentes al aceptar este tipo de préstamos encubiertos pero, sobre todo, al permitir que las filas de integrantes del primero, segundo y tercer grupo adelgacen día a día y, sobre todo, generación tras generación. Los sentimientos de los padres se potencian, para bien o para mal, en los sentimientos de los hijos. El espejo del alma no son los ojos.

Recuperar las pasiones en el mundo universitario - la capacidad para contemplar- es el único camino eficaz a largo plazo para que la universidad no acabe convertida en un cúmulo de palabras vacías y rituales estériles. O aún peor, en uno de los ámbitos profesionales más tóxicos, como señalan David Knights y Caroline Clarke en una investigación cualitativa sobre cómo "la apasionante vida del investigador docente" parece un ideal tan frecuente como irreal en el mundo universitario (Knights 2014).

Descendiendo de nivel, recuperar las pasiones es también la manera en la que la actividad interdisciplinar puede propiciar el progreso científico y social en el corto plazo. Y finalmente, a medida que se consiga ir cambiado el imaginario colectivo, es la estrategia de marketing más idónea para que las instituciones académicas llenen sus arcas. Mientras, habrá que buscar apaños que permitan a la universidad subsistir en tiempos de vacas flacas. Todo menos emplear esas destructivas estrategias cortoplacistas propias de jugadores caídos en la red de prestamistas. En términos similares se expresa 
Carlos Martínez Alonso, ex presidente del CSIC y ex secretario de Estado de Investigación, al tratar la nefasta moda de la mal llamada innovación científica:

Es innegable y necesaria la utilización del conocimiento, pero el platillo de la balanza está ahora inclinándose para dedicarse a lo inmediatamente práctico, a dar respuesta a las necesidades del mercado, a lo que denominamos innovación. Si no somos capaces de encontrar un equilibrio y desviamos la mayor parte de los recursos en esa dirección, quizá perdamos uno de los grandes valores que la ciencia ha aportado: su capacidad de transformar el mundo y su papel determinante en la evolución de la humanidad. (Martínez Alonso 2016)

No vale la excusa de las circunstancias, pues no es esta la primera época en la que los intelectuales pasan apuros. Hay que confiar en la suerte de la providencia. La anécdota que Aristóteles nos cuenta sobre las vicisitudes del primer gran filósofo, Tales de Mileto, sirve de aliento:

Gracias a sus conocimientos en astronomía pudo presumir, desde el invierno, que la recolección próxima de aceite sería abundante, y al intento de responder a algunos cargos que se le hacían por su pobreza, de la cual no había podido librarle su inútil filosofía, empleó el poco dinero que poseía en darlo en garantía para el arriendo de todas las prensas de Mileto y de Quíos; y las obtuvo baratas, porque no hubo otros licitadores. Pero cuando llegó el tiempo oportuno, las prensas eran buscadas de repente por un crecido número de cultivadores, y él se las subarrendó al precio que quiso. La utilidad fue grande; y Tales probó por esta acertada especulación que los filósofos, cuando quieren, saben fácilmente enriquecerse, por más que no sea este el objeto de su atención. (Política I, 11, 1259a)

El mal no está en utilizar el conocimiento para obtener ganancias sino en invertir la escala de valores. Es entonces cuando la pasión huye desbocada y el universitario cae en el peor tipo de proxenetismo pues, como deja entrever Aristóteles en esta narración, si está mal vender el cuerpo, peor es mercadear con las cosas del espíritu.

Son muchos los que, ahora como antes, tacharían a Tales de idealista -con la cabeza en las nubes y ajeno a los socavones del camino-. Pero son también esos hombres los que aplaudirían con vehemencia al Tales enriquecido, describiéndole como un hombre sobrio, desapegado, con los 
pies en la tierra - un pionero de la meteorología-. ¿Y las críticas antecedentes? No es fácil que reconozcan su error pues, quienes no entienden la diferencia entre ser práctico y ser pragmático, suelen andar también cortos de memoria... y de proyección.

Aún más fieros enemigos por combatir en la cruzada por recuperar la subjetividad en el mundo intelectual son los que dicen estar a favor de la interdisciplinariedad, del arte, de la comunidad académica. Lo que hacen las manos no es siempre lo que indican los labios, ni los labios siguen siempre al pensamiento. Pero la peor desconexión es la que existe entre el eslabón de la mente y el del corazón. A veces pensamos creer lo que no creemos y pensamos sentir lo que no sentimos. Mis últimas investigaciones me han conducido al fenómeno del auto-engaño sentimental, asunto sobre el que, sin duda, queda casi todo por dilucidar (Echarte 2014, Echarte et al. 2016). El camino de la autenticidad que enlaza esos cuatro eslabones me parece el mismo que el que facilita la reactivación de la investigación interdisciplinar: integrar la vida racional y afectiva. ¿Pero por dónde empezar? Cierro el epígrafe atreviéndome a ofrecer algunos consejos.

En primer lugar, es importante dedicar esfuerzos y tiempo a hacer comprender entre profesores y alumnos la diferencia entre reapasionar la ciencia y hacerle perder el vigor de la objetividad. Ciertamente, introducir el componente emocional exige que el intelectual aprenda a superar ciertas tentaciones asociadas a verse implicado en su trabajo, pero es crucial explicar que estas son más pequeñas que las que acompañan al no implicarse.

En lo que a la educación de la sensibilidad se refiere, mi experiencia me empuja a pensar que los profesores debiéramos empezar transmitiendo el gusto por resolver acertijos (evocar la excitación eureka), como base preparatoria para adquirir el gusto por alcanzar otros modos de pensar (inducir la catarsis narrativa), y terminar con el cultivo del gusto contemplativo por el cual descubrimos lo nuevo y eterno que habita en todas las cosas (abrir al alumno a la experiencia extática). Hay que reconocer, no obstante, que pueden existir otras vías para llegar a los sentimientos más elevados. La literatura, la música, la pintura, los paseos por el campo... son como los hábitos de higiene diaria, por ocupado que esté el investigador o el alumno, nunca debiera 
desatenderlos. Ahora bien, más importante aún para atraer a las musas es no olvidar que el fin último de la actividad intelectual no es el sentimiento sino la realidad, a la que este está supeditado. Y aquí la dificultad es preocuparse por los sentimientos de los alumnos sin inducir actitudes hedonistas.

Otro asunto de crucial importancia es aprender a valorar las emociones negativas en su justa medida. Hay circunstancias en las que las más provechosas reacciones son las de tristeza, miedo, vergüenza o enfado. Dichas emociones pueden servir también como indicador de la distancia existente entre las manos y el corazón. Porque hay una diferencia enorme entre aprender a no enfadarse y reprimir un enfado. La misma que la que existe entre aprender a apreciar algo y forzarse a ello. Lo segundo es en ocasiones necesario, pero utilizarlo como principal método de gestión emocional arrastra al individuo hacia su alienación. Expresar que el estudio de una materia aburre es mejor que fingir - fingirse- entusiasmo. Saberse aburrido es el primer paso para escapar del aburrimiento.

Un tercer ingrediente para reapasionar la ciencia, muy relacionado con el anterior punto, es el de promover un clima de confianza entre alumnos y profesores, lo que implica conceder cierto espacio a las emociones negativas. Esto tiene que ver con, dentro de unos límites razonables, saber valorar y aprovechar las discusiones acaloradas, puesto que son momentos en los que los participantes revelan la importancia que el interlocutor concede a lo pensado - este tipo de reflexión llevada al ámbito de la intimidad suele ser muy fructífera-. Cuesta mucho trabajo aprender a tener enemigos íntimos, pero con el establecimiento de este tipo de vínculo todos salen ganando. Esa es también la razón por la que igual de perjudicial que fomentar el miedo al profesor es no parar de regalar los oídos al alumnado. Si la primera medida oculta al alumno, la segunda oculta al profesor. En ambas circunstancias es difícil aprender de alguien, seguir a nadie. En la segunda se suma además el agravante de la doblez. Este tipo de manipulación evita la confrontación en el corto plazo pero, en el largo plazo, crea una desconfianza y resentimiento que termina por destruir lo poco de bueno que pudo haberse generado con el engaño paternalista. En fin, cuando una norma de educación no sirve para estrechar lazos sino para lo contrario, es mejor dejarla a un lado. 
Las mismas reglas sirven para la relación entre investigadores. Pero es pertinente hacer aquí una puntualización. Desde hace algunos años ha prosperado en el mundo académico la moda empresarial de convertir a los jefes en portadores de buenas noticias y de crear la figura del esbirro para trasladar las malas. Otra variante con similares consecuencias es hacer responsables de las malas noticias a desdibujadas e inaccesibles entidades superiores. No hace falta explicar por qué este tipo de gestión imposibilita la formación de verdaderas comunidades científicas. Aquí vuelve otra vez a sobresalir la idea de que la universidad es para esos valientes que no rehúyen su responsabilidad ni las confrontaciones porque, entre otras cosas, gozan de visión de futuro. La valentía debe conjugarse, por supuesto, con la humildad. Creo que un buen signo para decidir cuándo dejar un puesto directivo es ese momento en el que el peso del cargo supera la capacidad del individuo para mantener enemigos íntimos. Otro signo al que prestar atención es el del excesivo cultivo de la propia imagen o de la imagen corporativa pues estos son incompatibles con el cuidado de la dimensión sentimental de la propia vida y, por supuesto, de las ajenas.

Con lo dicho en el párrafo anterior debe quedar claro que el reto afectivo de la investigación interdisciplinar no consiste en lograr que profesores y alumnos pasen un buen rato con su trabajo. Si eso fuera así, sería relativamente sencillo discriminar a los buenos profesores y a los buenos alumnos. Pero no siempre los profesores más estimados del momento ni las asignaturas preferidas de un curso son las que necesariamente conducen, a la postre, a las más altas cimas sentimentales e intelectuales. Los ítems más importantes de la calidad universitaria únicamente pueden ser valorados a muy largo plazo y, en algunos casos, ni eso.

\section{Conclusión, el don apacible}

El tiempo pone a cada cual en su sitio. De muchos profesores carismáticos tan solo me queda el vívido recuerdo de su presencia, que es imposible de recuperar rebuscando en viejos apuntes. Y lo que es peor, en numerosas ocasiones dicho intento de viajar en el tiempo resulta contraproducente. 
Es el infierno imaginado de Juan Rufo: "Siempre vivió ella suspirando por Comala, por el retorno; pero jamás volvió. Traigo los ojos con que ella miró estas cosas" (Rujo 1997, 180). Pero la mirada de Pedro Páramo no es la mirada de ella -juventud, pasado- sino otra poblada de imágenes lúgubres. En contrapartida, de otros profesores solo me acuerdo por la importancia de la materia que impartieron y por su efecto en mi trayectoria vital. Qué magnífica disciplina. Lástima que el profesor no estuviera a la altura. Con la madurez, ese recuerdo se redimensiona con la sospecha de que tales profesores guardaron un papel mucho más relevante en el aprendizaje del que sus alumnos suponíamos: servir de guía hacia esa tan peculiar tercera ventana que exige al maestro apartarse.

La afirmación de Søren Kierkegaard de que la puerta hacia la felicidad se abre hacia dentro (Kierkegaard 2015, 43) resulta especialmente relevante en el buen aprendizaje del alumno pero también para la plenitud -incluso sentimental-del maestro. Sin embargo, tal estrategia de retroceso no resulta nada fácil dadas las circunstancias culturales aquí relatadas.

En su vuelta a Ítaca, Odiseo aparece disfrazado. No es una entrada regia pero, como proclama Ludwig Wittgenstein, las plazas de profesor no son para personas demasiado serias (Wittgenstein, Bouwsma 2004, 29). Paradójicamente, el filósofo de la vida oculta murió en el entorno de una de las mejores universidades de su tiempo, Cambridge. Y aunque lo hizo en casa de su médico, sus últimas palabras fueron, "Diles que mi vida fue maravillosa" (Monk 2002). Extrañas palabras para un hombre de carácter difícil. Conforta saber que el don apacible del profesor Artigas no es condición sine qua non para ver más allá de lo que el lenguaje es capaz de expresar. Si bien parece cierto que, en condiciones normales, dicho don ayuda.

\section{Bibliografía}

Álvarez, F. J., C. Medina, A. Alonso, y C. Silva. 1998. “Fenomenología de la mística y de la ascética.” Revista de la Asociación Española de Neuropsiquiatría 18/67:493-512. Aristóteles. 1988. Política. Madrid: Gredos.

Arnheim, R. 1954. Art and Visual Perception: A Psychology of the Creative Eye. Berkeley: University of California Press. 
Artigas, M. 2009. Filosofía de la ciencia. Pamplona: Eunsa.

Aunión, J. A. 2008. “Vago, a letras; empollón, a ciencias.” El País, reportaje, 30 de junio.

Benedicto XVI. Spe Salvi. Disponible en http://w2.vatican.va/content/benedict-xvi/ es/encyclicals/documents/hf_ben-xvi_enc_20071130_spe-salvi.html

Berger, A. 2002. “Arrogance among Physicians.” Academic Medicine 77/2:145-147.

Blix, A. G., R. Cruiseb, B. Mitchellc, and G. Blixd. 1994. “Occupational stress among university teachers.” Educational Research 36/2:157-169.

Bonnie, G. 1988. "The marketing of altruistic causes: understanding why people help.” Journal of Services Marketing 2/1:5-16.

Carson, R. 2012. El sentido del asombro. Madrid: Encuentro.

Conrad, J. 1945. Prefacio a The Nigger of the Narcissus. A tale of the Sea. London: Dent.

Cortés, J. M. 2016. “Entrevista realizada por Teresa Galarza.” Concedida para la revista Jot Down. Contemporary culture mag. 28 de abril.

Echarte, L. 2012. “Neurocosmética, transhumanismo y materialismo eliminativo.” Cuadernos de Bioética 23/77:37-51.

-. 2014. Hábitos emocionales en torno a la salud y la belleza. Pamplona: Astrolabio.

Echarte, L., J. Bernácer, D. Larrivee, J. V. Oron, and M. Grijalba-Uche. 2016. “Self-Deception in Terminal Patients: Belief System at Stake.” Frontiers in Psychology 7: 1-6. http://dx.doi.org/10.3389/fpsyg.2016.00117

Eco, U. 1999. Arte y belleza en la estética medieval. Barcelona: Lumen.

Eisenberg, D., S. Gollust, E. Golberstein, and J. Hefner. 2007. "Prevalence and Correlates of Depression, Anxiety, and Suicidality Among University Students.” American Journal of Orthopsychiatry 77/4:534-542.

Fortier, M., R. Vallerand, and F. Guay. 1995. "Academic Motivation and School Performance: Toward a Structural Model.” Contemporary Educational Psychology 20/3:257-274.

Gaitán, L., and L. Echarte. 2016. “Transforming Neuroscience Into An Emotional Meta-Narrative: A Critical Examination.” Techné: Research in Philosophy and Technology 20/1:16-33.

García Cuadrado, J. A. 2007. “D. Mariano Artigas. In Memoriam. Perfil biográfico y académico.” Scripta Theologica 39/2: 467-478.

Huxley, A. 2005. “La experiencia visionaria.” La experiencia mística y los estados de conciencia, editado por White John, 59-84. Barcelona: Kairós.

Kierkegaard, S. 2015. Diapsalmata. Paracuellos de Jarama, Madrid: Hermida Editores. Kingsley, P. 2014. En los oscuros lugares del saber. Gerona: Atalanta.

Knights, D., and C. Clarke. 2014. “It’s a Bittersweet Symphony, this Life: Fragile Academic Selves and Insecure Identities at Work.” Organization Studies 35/3:335-357. 
Kuhn, T. 1991[1968]. “The nature and Necessity of Scientific Revolutions.” The Philosophy of Science, edited by R. Boyd, P. Gasper, and J. D. Trout, 148-158. Massachusetts: Bradford Book.

Levine, T. R. 2014. "Truth-default theory (TDT): a theory of human deception and deception detection.” Journal of Language and Social Psychology 33:378-392.

Livet, P. 2010. "Rational choice, neuroeconomy and mixed emotions." Philosophical transactions of the Royal Society B 365/1538:259-269. doi: 10.1098/rstb.2009.0177

Martínez Alonso, C. 2016. El País Semanal, entrevista realizada por José María Izquierdo. 25 de mayo. Disponible en http://elpaissemanal.elpais.com/documentos/ carlos-martinez-alonso/

McCornack, S. A. 1992. "Information manipulation theory." Communications Monographs 59/1:1-16.

Meštrović, S. G. 1997. Postemotional Society. London: Sage.

Monk, R. 2002. Ludwig Wittgenstein. Barcelona: Anagrama.

Mosak, H., and Maniacci M. 1999. Primer of Adlerian Psychology: The Analytic - Behavioural: Cognitive Psychology of Alfred Adler. New York: Brunner Routledge.

Newman, J. H. 2011. Cristianismo y ciencias en la universidad. Pamplona: Eunsa.

Peat, D. 1991. The Philosopher's Stone. Chaos, Synchronicity and the Hidden Order of the World. New York: Bantam Books.

Peñalver Gómez, P. 1997. La mística española (siglos XVI-XVII). Madrid: Ediciones Akal.

Pfister, H. R., and G. Böhm. 2008. "The multiplicity of emotions: A framework of emotional functions in decision making." Judgment and decision making 3/1:5-17.

Polo, L. 1996. El profesor universitario. Piura: UDEP.

Rulfo, J. 1997. Pedro Páramo. Santiago: Editorial Universitaria.

Shem, S. 2002. La casa de Dios. Barcelona: Anagrama.

Silván, M. P., I. Cuadrado, y M. López-Sáez. 2012. “Estereotipos.” En Psicología Social, editado por I. Fernández e I. Cuadrado, 279-310. Madrid: Sanz y Torres.

Smith, A. 1982[1759]. The Theory of Moral Sentiments. Indianapolis: Liberty Classics. von Hippel, W., and R. Trivers. 2011. “The evolution and psychology of self-deception.” Behavioral and Brain Sciences 34:35-35.

Warma, S. 1984. “Ecstasy and Vision: Two Concepts Connected with Bernini's Teresa.” The Art Bulletin 66/3:508-511.

Wittgenstein, L., and O. K. Bouwsma. 2004. Últimas conversaciones con Wittgenstein. Salamanca: Sígueme. 